\title{
Three Faces of the Monster: Interpreting Disability and Creating Meaning in Translations of Alice Munro's “Child's Play”
}

This article addresses the problematics of creating meaning in literary translation by comparing three versions of Alice Munro's short story “Child's Play” translated into German, Ukrainian, and Russian. Proceeding from a fluid and unstable source text that represents the conflict of socially perpetuated normative thinking and non-conforming "monstrous" bodies marked by intellectual disability, the translators renegotiate the meaning of embodied otherness and its stigmatization in society in unique ways that reflect their personal perspectives on translation and individual agendas in their translation projects. Munro's focus on the relationship between a special needs girl and the narrator responsible for her death exposes the society's deeply ingrained aversion, fear, and hate against people with intellectual disabilities. These prejudiced views find their expression in equating "special" bodies with passive objects, repulsive animal-like creatures, and wild monsters. However, this metaphorical language reflects first and foremost on the narrator, whose hateful speech, breaking through the surface of her seemingly impartial account, unmasks the true faces of the victim and the perpetrator. Each translator ascribes a different meaning to Munro's deliberately ambiguous narrative: while the German version accentuates the original's insistence on complexity and uncertainty, the Ukrainian translation increases intensity of the protagonist's emotional involvement bringing her hatred and disgust to the extreme to make a point about social marginalization of the vulnerable other. The Russian text, conversely, rationalizes the narrator's actions and turns her tale into a deeply tragic personal confession to align it with a typical plotline of the Russian literary tradition. Overall, three target-language versions of the story add new dimensions to the original text and further destabilize it by consolidating their preferred readings in their treatment of the socially constructed opposition between "monstrous" and "normal". 